within its limited means, to meet the demand for qualified teachers and suitable teaching material. This includes direct teaching in twenty-five centres and institutes throughout the world, but mainly in southern Europe and the Middle East, with an aggregate of nearly 20,000 pupils; co-operation with educational authorities overseas, in training and advising teachers and in the preparation of syllabuses and text-books as well as seconding of officers for teaching duties ; assistance to non-official institutions engaged in organized teaching of English ; assistance in broadcasting English lessons; provision of facilities for overseas teachers to study in the United Kingdom; and the publication of periodicals devoted to the problems of the teacher of English. Of the eighteen full-time university posts subsidized by the Council at March 31, 1956, in Burma, Germany, Greece, Indonesia, Japan, Lebanon, Thailand and Turkey, all except one (the visiting professor of English literature at the American University of Beirut) were in Finglish.

Travel grants for study visits to the United Kingdom were made during the year to three university teachers or postgraduate research workers from Canada, nineteen from Australia, four from New Zealand, eight from South Africa, eleven from India, and three from Pakistan, while three grants were made for similar visits from the United Kingdom to Canada, two to Australia, three to South Africa and one each to New Zealand, Malaya and the West Indies. Visits from British universities to universities in 13 European countries during the academic year 1954-55 totalled 52, and United Kingdom universities received 55 visits from universities in these countries. Of the 4,472 overseas visitors to the United Kingdom during the yจar under the auspices of the British Council, 1,194 were concerned with education, 1,005 with social science, 874 with science and 817 with medicine, while 5,038 students were met on arrival, of whom 4,655 were from British Colonial territories and 120 from Commonwealth countries. Of these, 373 were provided with permanent accommodation in British Council hostels, 1,242 with transit accommodation in such hostels on arrival and 1,611 with temporary hostel accommodation while on study or recreation visits. Of the lecture tours and advisory visits overseas arranged by the Council, 33 per cent were in science, medicine, agriculture and engineering, and 26 per cent in education, sociology, philosophy and law.

Related to the teaching of English overseas is the support given by the Council overseas to British schools and schools run on British lines, and there is a keen demand for places in schools of this kind in many parts of the world. The Council is co-operating with the Iraq Government in establishing a new secondary school in Iraq on a site to be provided by the Iraq Government and is co-operating with the Libyan Government in establishing a new school in Libya. An extensive tour of schools in India run on the lines of British public schools was arranged early in 1956, and the Council is also in close touch with similar schools in Pakistan. In student welfare a main difficulty has been in securing suitable premises to replace the present inadequate Overseas Student Centre in Hanover Street. A notable event was the conference at Cambridge in July 1955, attended by 98 university rectors and other delegates from all the Western European Union countries, together with 16 rectors and representatives of other Council of Europe countries which discussed specialization and general culture; the autonomy and independence of universities; the selection, training and welfare of students; and the university and the community. In science the Council gives the highest priority to fostering closer contacts between overseas specialists and their opposite numbers in Britain. During the year, 55 per cent of the Council Scholars, 64 per cent of the United Nations Fellows, and more than half the visits organized under the Foreign and Commonwealth University Interchange Scholars were concerned with scientific subjects. An advanced course on radioactive isotopes in the University of Concepcion, Chile, was organized jointly by the Council and the Board of Trade.

Much of the Council's overseas expenditure is financed from its own earnings in local currency, and over the past two financial years only about onethird of its net Government grants was spent overseas. Of this $£ 950,000$, between one-third and one-half was spent in the sterling area. Against this has to be set certain invisible exports such as direct earnings in foreign currency from United Nations Fellows, Colombo Plan trainees, donations for special purposes and indirect earnings in foreign currency, such as the $£ 300,000$ or more spent privately in the United Kingdom by students, Council visitors, etc.

Sir David Kelly's impressions add to the popular appeal of the report and should help to remove some long-standing prejudices and misunderstandings. Sir David points to a restoration of confidence and the resumption of permanent recruitment which has been suspended since 1949 , but he stresses the inadequacy of the Council's resources for coping with the oppor. tunities offered to it, especially in European countries.

\section{ELECTROCHEMISTRY AND ELECTROLYTIC SOLUTIONS}

$7 \mathrm{HE}$ Physical and Inorganic Group of the Victorian Branch of the Royal Australian Chemical Institute held a three-day discussion meeting on "Electrochemistry and Electrolytic Solutions" during August 6-8, 1956, in the Chemistry Department of the University of Melbourne. The discussion was attended by one hundred and fifteen persons.

The meeting was opened by Prof. R. H. Stokes (University of New England, Armidale) with a paper on "Electrolyte Solutions". The remainder of the day was devoted to research contributions. The first, by Prof. R. A. Robinson (University of Malaya) and Prof. R. H. Stokes (University of New England, Armidale), dealt with "The Role of Viscosity in Conductance and Diffusion of Concentrated Electrolytes". While it is clear that the viscosity is predominant in determining conductance and diffusion, and the current theoretical expressions of Onsager and Falkenhagen require an additional term which must approximate to the first power of the viscosity, it is not clear what the exact viscosity function is. On the experimental side, a description was given of Prof. Stokes's apparatus for measuring transport numbers, in which the solutions are analysed conductometrically both before and after the run. The ratio of the conductance of any salt in water to that of the same salt in a solvent of different viscosity (for example, 10 per cent sucrose, 10 per cent glucose, 10 per cent mannose in water) is almost independent of the electrolyte, but it is not equal to the inverse 
ratio of the corresponding viscosities. This confirms that the first power of the viscosity is not that which determines the experimental properties. The next paper, by Mr. L. A. Woolf (University of New England, Armidale), on "Tracer Diffusion of Iodide Ion in Concentrated Chloride Solutions", dealt with the diffusion-rate of 10 per cent iodide ion in potassium chloride. This was measured in a porous glass disphragm cell, the iodide ions being titrated potentiometrically with silver-silver iodide electrodes. Good agreement was found with the results obtained by the capillary cell method, discussed by Dr. R. Mills (Australian National University, Canberra), in his paper "Diffusion Studies in Dilute Solutions". Dr. Mills considered the relative merits of the three different methods of meusuring diffusion rates with radioactive tracers: $(a)$ open-ended capillaries, $(b)$ diaphragm cells, $(c)$ capillary cells. Of these, open-ended capillaries seem to be best but lead to steadily falling diffusion coefficients. The study of the diffusion rate of sodium ion in sodium chloride gives a curve different in shape from that of Wang but still showing a shallow maximum with concentration. The difficulties of testing the theoretical expression for limiting diffusion soefficient of single ions at low concentration were discussed. A new apparatus was described for studying diffusion-rates at these low concentrations with continuous monitoring of the activity left in the capillary.

Prof. Robinson delivered a paper on "Mixed Electrolytes", in which he applied Glueckauf's volume statistics to derive an equation of the Harned type for mixed electrolytes. It emerges that $\alpha_{12}$ and $\alpha_{21}$ can be expressed as functions of parameters which depend only on those for pure electrolytes. This enables the properties of a mixed solution to be calculated approximately from the known properties of the constituents. A paper by Dr. H. A. C. McKay (Atomic Energy Research Establishment, Harwell) on "The Activity Coefficients of Nitric Acid, a Partially Ionized 1:1 Electrolyte" was read by Prof. Stokes. Dr. McKay pointed out that the activity coefficients of nitric acid in water appear to be anomalous when compared with those of strong electrolytes. Nitric acid solutions were treated temporarily as ternary systems containing water, ionized, and un-ionized nitric acid, and cross-differentiation relations were used for relating the experimental activity coefficients to the activity coefficients of the hypothetical, fully ionized nitric acid. The latter were then calculated with the help of spectrophotometric duta, and were shown to lie on a curve similar to those of strong electrolytes.

Dr. M. Spiro (University of Melbourne) discussed "Transference Numbers of Weak Electrolytes". For iodic acid, the dissociation consternt of which is $0 \cdot 167$ at $25^{\circ} \mathrm{C}$, the problems of measurement include the choice of a suitable non-gassing electrode and of appropriate indicator electrolytes. Boundaries for the $\mathrm{HIO}_{3} / \mathrm{KIO}_{3}$ system behave normally, but the velocities of $\mathrm{HIO}_{3} / \mathrm{H}_{3} \mathrm{PO}_{4}$ boundaries, although independent of the $\mathrm{H}_{3} \mathrm{PO}_{4}$ concentration, increase with increasing current. This current variation was studied in detail. Iodic acid obeys the DebyeHückel-Onsager theory as well as do strong electrolytes when the ionic strengths are used in place of the concentrations. "The Theory and Properties of Polyelectrolytes" were discussed by Prof. D. O. Jordan (University of Adelaide), with particular attention to electrostatic potential, colligative prop- erties, and properties dependent on the shape of the polyion. T'he dissociation constant of a polymeric acid changes with the degree of ionization. The relation between $p K$ and $p H$ is complicated and involves the free energy change occurring when the charge on a polyacid is changed. This is equivalent to evaluating the surface potential of the polyacid.

The second section dealt with "Electrode Processes", and was opened by a review paper from Dr. B. Breyer (University of Sydney). The fine structure of the double layer, particularly that pictured by Grahame for a mercury surface, was discussed. The first research contribution in this session was on the "Criteria of Electro-reversibility", by Dr. S. Hacobian (University of Sydney), who dealt with general aspects of reversibility from the thermodynamic and kinetic points of view. Particular distinction was drawn between the reversibility of electrochemical reactions and the reversibility of the electrode process. The term 'reversibility' of electrode process is losing its original thermodynamic significance since it frequently refers to a particular set of experimental conditions. Mr. D. J. Casimer next delivered a paper on "Hydrogen Discharge Catalysis by Organic Heterocycles", with Dr. L. E. Lyons and Mr. A. J. Harle (University of Sydney) as co-authors. By studying the effects of quinoline derivatives, the mechanism of hydrogen discharge can be investigated. The catalytic effect of reduced quinolinium ion depends on the concentration and the $p H$, but is independent of the area of the dropping electrode, and disappears at large negative potentials. The results may be explained in terms of adsorption of the catalyst on the mercury gurface. At negative potentials the catalyst is desorbed and the wave disappears. The adsorbed catalyst is protonated by reaction with the buffer, with production of hydrogen. Dr. S. Hacobian read the paper by Dr. H. H. Bauer (University of Sydney) on "Electrode Processes in Organic Polarography". Organic substances are adsorbed at the electrode even when the d.c. polarograms provide no indication of such adsorption. Thus a.c. polarography or a similar technique is imperative if the full mechanism of the reduction of an organic compound is to be elucidated.

"Electrode Potential Studies in Passivity" was the subject of the contribution by Mr. W. T. Denholm (University of Adelaide). He first described the electrochemical techniques employed in the study of the properties and mode of growth of passive films. The results of an investigation of the passive behaviour of iron in a vuriety of buffer solutions free from inhibiting anions were presented. The passive behaviour of iron approaches that of the noble metals most closely when the $p \mathrm{H}$ is about $11 \cdot 5$. It is then covered with approximately a monolayer of adsorbed oxygen. The film grows by discharge of hydroxyl ions on to surface atoms which retain their metallic lattice sites. Growth does not begin until the potential reaches the level at which ferrous ions may dissolve. Mr. K. F. Lorking (Aeronautical Research Laboratories, Melbourne) followed with a contribution on "An Experimental Investigation of the Double Layer at Working Electrodes". An electrode of large surface area (in comparison with the volume of the electrolyte) is used for producing a significant change in concentration of ions participating in the double layer process. Gold powder is used as an electrode as it is a soft metal having a thin oxide film. Salts with anions which are not strongly adsorbed at mercury surfaces are chosen as electro- 
lytes. Solutions of nitrate, perchlorate and sulphate show $p H$ changes as the anode potential is increased, with variations in the rate of change of $p \mathrm{H}$ with potential over the potential range corresponding to oxide formation. These results demonstrate the influence of anode potential on the distribution of hydrogen and hydroxyl ions in the electrical double layer. Dr. J. H. Bradbury (Commonwealth Scientific and Industrial Research Organization, Wool Textile Research Laboratories, Geelong) discussed the "Theory of Dead-stop Titration". Particular attention was directed to the titration of $\mathrm{Fe}^{2+}$ with $\mathrm{Ce}^{4+}$. The current can be shown by thermodynamic argument to be dependent on the $\mathrm{Fe}^{2+}$ concentration, and hence on $i / k_{1}$, the ratio of the current between the electrodes to the diffusion constant in Fick's equation. From graphs of $i / k_{t}$ against volume of titrant the importance of various variables can be assessed. Greater accuracy is obtained by working at low voltages (about $0.010 \mathrm{~V}$.). In addition, accurate titrations between $10^{-4} \mathrm{~N}$ reagents should be possible provided they form reversible redox systems, the standard electrode potentials of which differ by more than $0 \cdot 20 \mathrm{~V}$. The final paper in this session, entitled "Direct Current Polarography of the Ferrous-Ferric Systems in the presence of Alternating Voltages", was given by Mr. G. S. Buchanan (New South Wales University of Technology). If an a.c. voltage is superimposed on the normal d.c. potential, rectification of the a.c. current will occur, depending on whether or not the electrode process is reversible. Application of this principle to polarography of the ferrous-ferric oxalate system was reported in some detail, together with the results obtained by adding surface-active substances such as cyclohexanol.

The first paper in the third session, concerned with applications of electrochemistry, was delivered by Prof. D. O. Jordan and was entitled "Charge Determination in Poly-electrolytes". While there are a number of possible methods for determining the charge on the polyion, only the electrophoretic mobility or electrical transport provides information which is easily interpreted. The former suffers from the disadvantage that the size of the ion is not usually sufficiently accurately known. The ionic charge can be determined by the method of Huizenga, Grieger and Wall ( $J$. Amer. Chem. Soc., 72, 2636; 1950), using sodium-22 as a tracer to measure the change in concentration of sodium in the electrode compartment of a Hittorf transference cell. The charge on the polyion decreases with decreasing polyion concentration down to low concentrations and then increases. Mr. E. F. Woods (Commonwealth Scientific and Industrial Research Organization, Wool Textile Research Laboratories, Geelong) followed with a paper entitled "The Application of Moving Boundary Electrophoresis to the Interaction of Proteins with Ions". Some examples were given of the application of the method to the study of antigen-antibody and protein-detergent reactions. Difficulties in interpreting electrophoretic effects were illustrated with reference to electrophoresis of proteins in acids containing amino-acid buffers. Dr. J. A. Friend (University of Tasmania) next presented. a paper in collaboration with $\mathrm{Mr}$. N. K. Roberts on "A Polarographic Study of some Würster Salts". At the dropping mercury electrode, and at a platinum micro-electrode, aromatic para-diamines give welldefined anodic waves in solution. Solutions of the Würster salts derived from these give either single waves (entirely cathodic) or double waves with both cathodic and anodic components. One electron is involved in each step. In "Amperometric Titrations of Molybdenum and Arsenic", Mr. G. H. Aylward (New South Wales University of Technology) showed that molybdates may be determined in concentrations of about $0.3 \mathrm{mgm}$. Mo/50 ml. (accuracy $\pm 0.001 \mathrm{mgm}$.) by titrating with lead nitrate in a supporting electrolyte of sodium acetate-potassium chloride of $p \mathrm{H} 3 \cdot 5$. At the potential selected, $-0.8 \mathrm{~V}$. versus standard calomel electrode, both lead and molybdate ions are reduced. Arsenates are not reduced in this solution, though they are reduced at $p \mathrm{H} 6.0$ if the acetate is free from chloride.

The last afternoon was devoted entirely to industrial applications. The first paper was on "Fused Electrolysis", by Prof. E. C. R. Spooner (University of Adelaide). Lead is extrected from galena at Port Pirie by direct electrolysis in molten lead chloride at $500^{\circ} \mathrm{C}$. using bipolar electrodes (Halkyn process). The current efficiency increases, and the applied voltage decreases with increasing concentration of lead sulphide, because of the depolarizing reaction of $\mathrm{Pb}+\mathrm{PbS} \rightarrow \mathrm{Pb}_{2} \mathrm{~S}$. This process for obtaining lead is potentially quite feasible, but much more work is needed before it can be regarded as established. Mr. A. S. Gill (Electrolytic Zine Co., Ltd., Hobart) followed with "Some Aspects of Hydrogen Cell Operation". In the commercial production of electrolytic hydrogen, resistance losses and over-voltages can easily account for 50 per cent of the applied voltage. The use of a high operating temperature $\left(75^{\circ} \mathrm{C}.\right)$, a potassium hydroxide electrolyte and iron cathodes with low hydrogen over-voltage helps to reduce theso losses, while nickel-plated anodes are satisfactory for resisting oxidation and solution. Since impurities are cumulative, the feed water must be of high purity. Zinc, lead and chloride impurities and deposition of iron with puncturing of diaphragms are the chief troubles encountered. Dr. A. Walkley (Division of Industrial Chemistry, Commonwealth Scientific and Industrial Research Organization, Melbourne) delivered a paper in collaboration with Mr. D. F. A. Koch and Mr. H. R. Skewes entitled "Some Problems in the Electro-winning of Copper". Recent methods of roasting copper-iron sulphide ores result in calcines containing oxides and sulphates of copper and iron so that, when leachates prepared from them are electrolysed, sulphuric acid builds up in the circuit. Solutions containing $\mathrm{H}^{+}, \mathrm{Fe}^{3+}$ and $\mathrm{Cu}^{2+}$ have thus to be stripped of copper before being discarded. The deposition of excessive copper from such solutions at an economic current efficiency presents many problems. The significance of turbulent and non-turbulent flow in the electrolyte was discussed. Small amounts of molybdenum have been found to be co-deposited with the copper, causing changes in its physical properties.

A contribution from Dr. C. S. Hocking (I.C.I.A.N.Z. Research Laboratories, Melbourne) followed. The theory of ion-exchange membranes was applied to a number of industrial problems, including water purification, caustic soda production, and acid recovery from spent liquors. Dr. M. Spiro read the last paper, on "The Effect of Current Density on the Transport of Ions through Ion Selective Membranes", by Dr. T. R. E. Kressman and Mr. F. L. Tye (Permutit Company, Ltd., Sydney and London). A method was described for measuring directly transport numbers in multicompartment electrodialysis cells at current densities and concentration differences 
similar to those used in practice. At high current densities, the ions are transported through 'Permaplex' $C-10$ and $A-10$ membranes faster than they can get to the membrane interface. At low current densities the transport numbers decrease with decreasing current density because concentration diffusion partially counteracts the electrical migration. When this effect is allowed for, the true transport number of the sodium ion in 'Permaplex' $C-10$ in $0 \cdot 1 \mathrm{~N}$ solution is found to be 0.98 , and its diffusion coefficient $8.1 \times 10^{-8} \mathrm{~cm}^{2} / \mathrm{sec}$.

J. F. DUNCAN

\section{RAINFALL STATISTICS IN THE BELGIAN CONGO}

$\mathbf{N}$ standard books of climatology published even since 1945 laments are to be found about the scanty nature of the data on the rainfall of equatorial forest areas. This reproach is now being rapidly removed and nowhere more rapidly than in the Belgian Congo, where the National Agronomic Institute has published during the past fow years several detailed papers by F. Bultot. In a recent publication*, M. Bultot presents the first analysis, using modern statistical methods, of the rainfall regime in an equatorial continental tropical region without a monsoon wind regime. Rainfall in the Congo falls in scattered thundery downpours. The data used cover twenty-nine years for Eala in the north-west and for varying periods of more than twenty years for fourteen other stations in the area.

The problems investigated are the frequency of falls of different intensity, the probability for two or more days of rain exceeding $15 \mathrm{~mm}$. to occur in succession, and the variation in the intensity of rainfall during $a$ shower. It is found that rain of more than $0.1 \mathrm{~mm}$. falls on one day in four and that the number of days in a year of $15 \mathrm{~mm}$. or more of rain is less than ten or more than sixty on less than one year in twenty, and the number of days of $50 \mathrm{~mm}$. and $80 \mathrm{~mm}$. can only exceptionally exceed twelve and four, respectively. There is a marked annual variation, corresponding to the movement with the Sun of the tropical rainbelt, of days with $15 \mathrm{~mm}$. or more of rain and a much less marked one, except in the central Congo where it vanishes, of days of $50 \mathrm{~mm}$. or more.

A very interesting fact is that there is no per. sistence of heavy rainfalls. The probability, in fact, that $15 \mathrm{~mm}$. or more will fall on the day following one with such amount is practically equal to the overall probability of a daily fall of that amount. In temperate regions there is appreciable persistence for rain days as a whole, though the degree of persistence for amounts of $15 \mathrm{~mm}$. or more does not appear to have been investigated. The daily maximum expected to be exceeded only once in ten years is about $120 \mathrm{~mm}$. and once in fifty years is $150 \mathrm{~mm}$. It is pointed out that in Ireland the corresponding values are $64 \mathrm{~mm}$. and $81 \mathrm{~mm}$.

Study of a number of individual falls shows that the rate of rainfall is heaviest within a quarter of an hour from the beginning and rarely exceeds $2 \mathrm{~mm}$. per minute. Only about 25 per cent of all falls

- Publications de l'Institut National pour l' Etude Agronomique du Congo Belge : Etude Statistique des Pluies Intenses en un Polnt et sur une Aire au Congo Belge et au Ruanda-Urundi. (Bureau ClimatoInstitut National pour l'Etude Agronomique du Congo Belge, 1956.) n.p. continue for more than four hours. The common opinion that tropical showers almost always occur in the afternoon is incorrect. It is found, however, that at most places there are relatively few showers during the morning. The afternoon showers are shorter and more intense than those at night. Finally, in a restricted study of area rainfall it is found that over areas up to $175 \mathrm{sq} . \mathrm{km}$. the frequencies of a given amount diminish exponentially with the area.

There is no discussion of the synoptic meteorology of rain. Perhaps in a future publication M. Bultot will investigate such matters as the incidence of showers or absence of showers over wide areas and the corresponding stream-lines of wind flow.

G. A. BULL

\section{LVOV GEOLOGICAL SOCIETY}

THE Lvov Geological Society celebrated in 1956 the tenth anniversary of its foundation. Lvov Geological Society is attached to Ivan Franco's State University of Lvov, founded in 1661. There the teaching of geology began at the end of the eighteenth century, when the chair of geognosy and oryktognosy was founded, no doubt under the impulse of the prevalent Wernerianism. In 1852 a mineralogical museum and in 1864 a chair of mineralogy were established. The first professor of mineralogy was Ferdinand Zirkel (1838-1912), the distinguished pioneer of microscopical petrography. It was during his residence in Lvov (1864-68) that Zirkel published his "Lehrbuch der Petrographie" (1866).

The Lvov Geological Society is now a very vigorous institution, comprising more than a hundred and twenty members. It is subdivided into a mineralogical section, presided over by Prof. E. K. Lazarenko, and a regional geology section by Prof. O. S. Vyalov. There is also a branch at the Chernovtzy State University. The principal object of the Society is the promotion of the study of geology, petrology, mineralogy and mineral deposits of the Western Ukraine, as well as other parts of the Soviet Union. It is interesting to note, however, that many contributors to its periodical publication reside in places distant from Lvov and even outside the Soviet Union, for example, in Bulgaria, China and Bolivia. The Society, besides its normal activities, has two special functions, namely, the organization of special surveys or studies in either pure or applied geology, and also of conferences. The Society has already undertaken the following surveys: a geophysical survey of Lvov region; a geological and geomorph. ological survey of certain Carpathian regions; $a$ petrographical and mineralogical study of igneous and sedimentary rocks; and finally, a specially organized survey of the Eastern Transbaikal region in Siberia. The conferences organized by the Society comprise the subjects of tectonics, stratigraphy, petrology, economic geology and history of geology.

The publications of the Society are: (1) Mineralogichesky Sbornik (Mineralogical Magazine), each annual volume of some 400 pages containing about forty original papers; (2) Trudy (Transactions) of Lvov Geological Society, comprising geological, petroleum geology and petrographical series; (3) Geologichesky Sbornik (Geological Magazine), replacing Trudy since 1955 ; (4) monographs on the petrology of the Ukrainian crystalline massif, granite plutons of Kazakhstan, migration of oil, tourmaline, bentonite clays, the Eastern Transbaikal region and Aldan 